\title{
Home Education Impact on Peritoneal Dialysis-Associated Peritonitis Episode
}

\author{
Fatma Abdelalim Abdelghany Ibrahim, 1, , , Amany Hassen Abdelsattar ${ }^{1,3}$ \\ ${ }^{1}$ Faculty of Nursing, Taibhah University, Medina, Saudi Arabia \\ ${ }^{2}$ Faculty of Nursing, Department of Community Health Nursing, University of Fayoum, Fayoum, Egypt \\ ${ }^{3}$ Faculty of Nursing, Department of Medical surgical nursing, University of Tanta, Tanta, Egypt \\ Email address: \\ fatmasefaan@gmail.com (F. A. A. Ibrahim), fatmasefaan@yahoo.com (F. A. A. Ibrahim)
}

\section{To cite this article:}

Fatma Abdelalim Abdelghany Ibrahim, Amany Hassen Abdelsattar. Home Education Impact on Peritoneal Dialysis-Associated Peritonitis Episode. American Journal of Nursing Science. Vol. 4, No. 4, 2015, pp. 154-158. doi: 10.11648/j.ajns.20150404.12

\begin{abstract}
The present study was aimed to evaluate the impact of home education on peritoneal dialysis (PD)-associated peritonitis episode in Al Medina- KSA. Thirty patients' on home PD were identified during their follow up visits to three dialysis units. Data were collected through three structured interviews questionnaire at their home via three tools; sheet for demographic characteristics and PD data and history, pre-posttests questionnaire for knowledge, and observational checklist for practice. Peritonitis episodes indicated by three cultures which were done at the times of; pretest, 3 and 6 months after posttest one. The main study findings revealed that $73.3 \%$ of the subjects were males with mean age of 26 year. A highly significant differences were found among pre and posttest one of knowledge part $\{\mathrm{t}(27.892) \mathrm{p}<(0.001)\}$, pretest-posttest one and posttest one- two of practice part, $\{\mathrm{t}(8.475) \mathrm{p}<(0.001)$ and $\mathrm{t}(4.805) \mathrm{p}<(0.001)\}$ respectively. The three consecutive cultures results were showed peritonitis episode as followed $(30 \%, 10 \%$ and $13.3 \%)$. Positive impact was showed on minimizing peritonitis episode in PD patients following home education but by time spent the patients' compliance declined. Thus periodical refreshment home education provided by experienced nurses is critically needed to maintain standardized PD practice.
\end{abstract}

Keywords: Home Education, Peritoneal Dialysis, Peritonitis

\section{Introduction}

Peritoneal dialysis (PD) is an accepted treatment modality for end stage renal diseases patients'. Over $65 \%$ of patients are receiving $\mathrm{PD}$ live in developing countries. PD modality is offering patients an effective treatment that can be carried out at home and benefits patients' quality-of-life, representing lower costs to the health care system. Out of 12,633 dialysis patients', 1196 of them were on peritoneal dialysis by the end of the year 2010. At the same time, 520 new patients have been registered at the year 2011 on peritoneal dialysis [1-3].Two main types of peritoneal dialysis schedules are possible. The first type is continuous ambulatory peritoneal dialysis (CAPD) involves multiple exchanges during the day usually three with an overnight dwell. The second type is the continuous cycler peritoneal dialysis is an automated form of peritoneal dialysis (APD) in which a machine performs exchanges while the patient sleeps; there may be a long daytime dwell and, occasionally, a manual daytime exchange [3].
One of the most serious complications of peritoneal dialysis is peritonitis, which can develop because bacteria can enter the abdomen through or around the peritoneal dialysis catheter. Peritonitis was defined as clinical suspicion based on any of the following symptoms or signs; cloudy PD effluent, fibrin clots in PD effluent, abdominal pain, nausea, vomiting, diarrhea, constipation, fever, chills, abdominal tenderness, rebound tenderness, weakness, and oral temperature $\geq 37.8^{\circ} \mathrm{C}$, together with peritoneal leukocyte count of $100 / \mathrm{ml}$ or more. These infections can usually be treated at home and resolve completely. Left untreated, peritonitis can become a life-threatening infection. Treatment typically requires one or more antibiotics, which are commonly given with the dialysate [3-4].

Concerning peritonitis prevention, the PD patients' should demonstrated the procedure safely and effectively, trained to wash their hands before touching their catheters, clean their exit sites every day, wear surgical masks when doing exchanges and check solution bags for contamination. Also, patients are trained to spot the signs of an infection, include irritation around the catheter. PD training usually takes one to 
two weeks. Training is given to the patient as well as the patient's caregiver, if $\mathrm{s}$ /he has someone who helped with the PD procedure. Patients' need space to store PD supplies, running water, electricity and a sterile environment to do their exchanges. However, home training PD nurses should not be leave a patient alone to do his or her treatments until both the nurse and the patient feel that training has been completed and the patient is comfortable performing the treatments [5].

\subsection{Aim of the Study}

The present study was conducted to evaluate the impact of home education of knowledge and practice on peritoneal dialysis-associated peritonitis episode in Al Medina- KSA.

\subsection{Specific Objectives}

1- To assess the differences of knowledge and practice levels regarding PD at the pre, posttests one and two of home education.

2- To evaluate the peritoneal episode in relation to pre, posttests one and two of home education.

\section{Material and Methods}

\subsection{Design}

By utilization of quasi-experimental time series design the present study was conducted.

\subsection{Target Population}

A purposive sample of thirty patients' on home peritoneal dialysis modality for a minimum of six months were recruited. The study participants' were identified during their follow up visits to three dialysis units in Al Medina - KSA. The data collected between periods of January 2013 to December 2013.

\subsection{Tools for Data Collection}

Three tools were utilized to collect pertinent data included; I- Sheet for demographic data such as; age, sex, educational level, social status....etc, another sheet to collect data and history of PD modality and peritonitis such as; types of PD, period of PD therapy, numbers of peritonitis episode during the previous year, source for information and education ..etc. The second tool was pre-posttests questionnaire for knowledge part incorporated; definition, signs and symptoms, observations of the exit site, infection control, and environmental sanitation. Total knowledge questions was 42 point, scored as $(0=$ unknown or wrong answer and $1=$ correct answer). The third tool was pre-posttests of standardized observational checklist of home PD practice part. Total items was 21 steps, scored as $(0=$ not done or incorrect and $1=$ done and correct). Peritonitis episode in the present study was detected by three cultures which done at the times of the pretest, three and six months after posttest one. The operational definition of peritonitis in the present study was white blood cell (WBC) count $>100$ cells $/ \mathrm{mm}^{3}$ in the affluent sample taken, after a minimum dwell time of four hours [6]. A pilot study was done on $10 \%$ of the study participants to assure clarity and understanding of the tools. It also helped in the estimation of the time needed to fill the data collection tools. Accordingly, some minor modifications were made to the tools.

\subsection{Procedure}

The data collection was carried out through four structured interviews at patients' homes. Each interview took an average 60 to 90 minutes to complete. Data collections were carried out sequenced of pretest, posttest one after education, posttest two for knowledge and practice after six months from the posttests one. Cultures as peritonitis indicators were done at the pretest, three and six months after posttest one The demographic data and pretests of knowledge and practice at the first interview were followed by education for both knowledge and practice. The impact of PD home education was correlated with the episode of peritonitis along 6 months post home education.

\subsection{Home Peritoneal Dialysis Education}

Based on literature review [7], a simple language booklet with illustrated pictures was developed by the researchers, in addition to video film produced by [8]. The booklet mentioned definition, signs and symptoms, causes, management of peritonitis. Also, home modification, facilities, sanitation and infection control were involved. Early understanding and intervention of difficulties that may be arises to PD patient in relation to infections, in addition the booklet covered the checklist of the PD procedure, in which the guidelines documented by [9] adopted in the implementation of the home education for both knowledge and practice parts, such as asking the PD patient to guess if it might be peritonitis, use of pairs, one very likely, one very unlikely, moved on to another pair not so easily differentiated (clear, very cloudy, clear, slightly cloudy). For the practical part, the following steps were demonstrated; the PD patient described or read each step; then researcher performed them, patient did not practice procedure until $\mathrm{S} /$ he able to described each step, the patient practiced the procedure using model with $\mathrm{PD}$ catheter, described each step as performed, and when S/he able to perform procedure successfully, patient performed procedure using own catheter. Considering practice rules, the PD patient supervised when $\mathrm{S} /$ he was able to do the $\mathrm{PD}$ procedure successfully, with immediate feedback from the researcher, telling what doing right, stop when mistake made (not later), redirect patient to place where no mistakes made and guided $\mathrm{him} /$ her through problem areas.

\subsection{Ethical Considerations}

A clear explanation of the nature and the aim of the study were given to the PD patients' to obtain their informed verbal consent which included their rights for privacy and confidentiality during the orientation visit of the dialysis units. Tools for data collection were completed anonymously for confidentiality. 


\subsection{Statistical Analysis}

The data collected were tabulated and analyzed using SPSS version 16. Descriptive and inferential statistics were carried out included; frequencies, percentages, chi-squared test for qualitative variables, and paired t-test for quantitative variables. The level of significance was set at 0.05 .

\section{Results}

Table 1 describes the demographic characteristics according to the peritonitis episode of the present study participants. The mean age score \pm SD was $26 \pm 12$, males represented two third of the study participants, nearly two third were single and childhood ( $30.1 \& 33.3 \%)$ respectively. All of these variables showed in significant differences with the peritonitis episode $(\mathrm{P}<0.05)$. Also, $20 \%$ of the study participants' were illiterate with no significant differences with peritonitis episode $(\mathrm{P}>0.05)$.

Table 1. Demographic characteristics of the study participants according to peritonitis episode percentages of the study participants $(n=30)$.

\begin{tabular}{|c|c|c|c|}
\hline \multicolumn{2}{|c|}{ Variable } & \multirow{2}{*}{$\begin{array}{c}\mathbf{N o}=\mathbf{3 0}(\mathbf{\%}) \\
10(33.3)\end{array}$} & \multirow{2}{*}{$\begin{array}{l}\text { Peritonitis episode at the } \\
\text { Pre- posttests one and two } \\
\text { Mean } \pm \text { SD } 26 \pm 12\end{array}$} \\
\hline Age: & $9-18 y$ & & \\
\hline & $>18-40$ & $16(53.4)$ & \\
\hline & $>40$ & $4(13.3)$ & $X^{2}(7.200), \quad P(0.027) S * *$ \\
\hline \multirow[t]{2}{*}{ Sex : } & Male & $22(73.3)$ & \\
\hline & Female & $8(26.7)$ & $X^{2}(6.533), \quad P(0.011) S * *$ \\
\hline \multicolumn{4}{|c|}{ Level of Education } \\
\hline & Illiterate & $6(20)$ & \\
\hline & Basic & $8(26.7)$ & $\mathrm{X}^{2}(4.333), \quad \mathrm{P}(0.363)$ N.S*** \\
\hline & Secondary & $10(33.3)$ & \\
\hline & University & $6(20)$ & \\
\hline \multicolumn{4}{|c|}{ Social Status } \\
\hline & Single & $9(30.1)$ & \\
\hline & Married & $10(33.3)$ & $X^{2}(8.133), \quad P(0.043) S^{* *}$ \\
\hline & Divorced & $1(3.3)$ & \\
\hline & Childhood & $10(33.3)$ & \\
\hline
\end{tabular}

H.S *= highly significant at the 0.01 level, $\mathrm{S} * *=$ Significant at the 0.05 level. N.S*** = no significant

Table 2 shows the PD and peritonitis history according to peritonitis episode of the study participants. Family caregivers of PD patients' represented (36.7\%). Regards type of PD, it was found that $(60 \% \& 40 \%)$ on CAPD and APD respectively, with no significant differences with peritonitis episode $\mathrm{P}>0.05$. More than half of study sample were in PD for a period ranged from 1:5 years, and have had between once and twice episode of peritonitis $(53.3 \% \& 56.7 \%$ respectively). The majority was educated about wound care $(83.3 \%)$. The nurse and physician were the source of home PD education for (30\% \& $63.3 \%$ respectively), while, $(6.7 \%)$ were received their education from previous patient. The minority $(3.37 \%)$ was having pervious technique failure and shifting to hemodialysis. All of these variables were found in highly significant differences with peritonitis episode $\mathrm{P}<0.01$.
Table 2. PD and peritonitis episodes history according to peritonitis episode percentages of the study participants $(n=30)$.

\begin{tabular}{|c|c|c|}
\hline Variable & $\mathrm{No}=\mathbf{3 0}(\%)$ & $\begin{array}{l}\text { Peritonitis episode at the pre- } \\
\text { posttests one and two }\end{array}$ \\
\hline \multicolumn{3}{|c|}{ Tools for data collection filled by: } \\
\hline The patient & $19(63.3)$ & $\mathrm{X} 2(2.133)$, \\
\hline Family caregiver & $11(36.7)$ & $\mathrm{P}(.144) \mathrm{NS} * * *$ \\
\hline \multicolumn{3}{|l|}{ Type of PD } \\
\hline CAPD & $18(60)$ & X2 (1.200), \\
\hline APD & $12(40)$ & $P(0.273)$ N.S*** \\
\hline \multicolumn{3}{|c|}{ Duration of PD therapy } \\
\hline Less than $1 \mathrm{y}$ & $6(20)$ & \\
\hline $1-5 y$ & $16(53.3)$ & \\
\hline$<5-10 y$ & $7(23.4)$ & X2 (15.600), \\
\hline$>10 y$ & $1(3.3)$ & P (.001) H.S* \\
\hline \multicolumn{3}{|c|}{ Episodes number of peritonitis during the last year } \\
\hline 1 st & $9(30)$ & \\
\hline 2nd & $8(26.7)$ & X2 (10.800), P (0.001) H.S* \\
\hline $3 \mathrm{rd}$ & $4(13.3)$ & \\
\hline 4th & $7(23.3)$ & \\
\hline 5th & $2(6.7)$ & \\
\hline \multicolumn{3}{|c|}{ Is the patient educated about wound care? } \\
\hline Yes & $25(83.3)$ & X2 (13.333), P (0.000) H.S* \\
\hline No & $5(16.7)$ & \\
\hline \multicolumn{3}{|c|}{ Sources of home PD education } \\
\hline Nurse & $9(30)$ & X2 (20.400) \\
\hline Physician & $19(63.3)$ & $\mathrm{P}(0.000)$ H.S* \\
\hline Previous patient & $2(6.7)$ & \\
\hline \multicolumn{3}{|c|}{$\begin{array}{l}\text { Is the patient have previous technique failure because of peritonitis } \\
\text { ( shifting from PD to HD)? }\end{array}$} \\
\hline Yes & $1(3.3)$ & X2 (26.133), P (0.000) H.S* \\
\hline No & $29(96.7)$ & \\
\hline
\end{tabular}

H.S *= highly significant at the 0.01 level. $\mathrm{S} * *=$ Significant at the 0.05 level. N.S*** = No significant

Figure 1 illustrates the percentage of peritonitis episode as the following $(30 \%, 10 \%$ and $13.3 \%)$ at the times of pretest, three and six months after posttest one These episodes found correlated to the mean scores of knowledge \& practice at the times of pretest, posttests one and two (13.2, 39.3 and 38.9) of knowledge respectively, and (17.7, 20.4 and 19.6) of practice respectively.

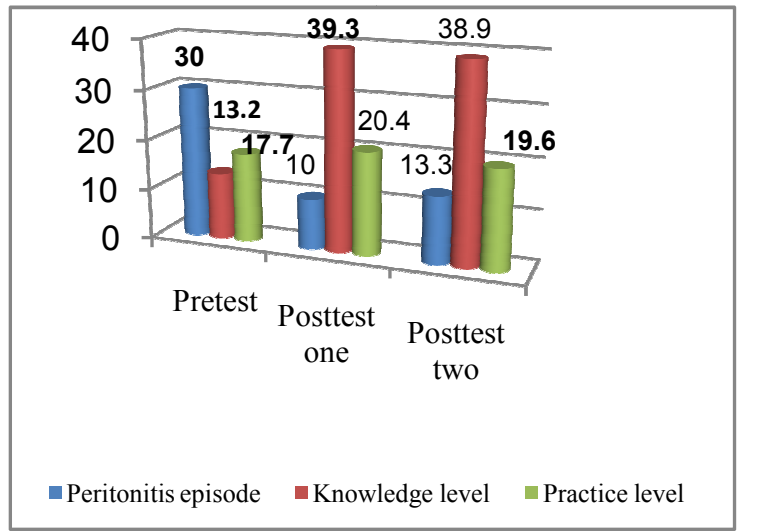

Fig. 1. Percentages of peritonitis episode correlates to means scores of knowledge and practice level of pretest, posttests one and two of the study participants $(n=30)$.

Table 3 represents percentages of noncompliance knowledge and practices variables during pretest, posttests one and two of the study participants. Knowledge about 
infection control, hands not washed, adherence to aseptic technique and work surface not cleaned variables showed level of improvement between the pretest and posttest one. Meanwhile, all of these variables showed noncompliance of the posttest two.

Table 3. Percentages of noncompliance knowledge and practices variables during pretest, posttests one and two of the study participants $(n=30)$.

\begin{tabular}{lccl}
\hline $\begin{array}{l}\text { Noncompliance } \\
\text { knowledge and practices }\end{array}$ & $\begin{array}{l}\text { Pretest } \\
\text { No (\%) }\end{array}$ & $\begin{array}{l}\text { Posttest one } \\
\text { No (\%) }\end{array}$ & $\begin{array}{l}\text { Posttest two } \\
\text { No (\%) }\end{array}$ \\
\hline \multicolumn{2}{l}{ Knowledge about infection control } \\
$29(96.7)$ & 0 & $13(43.3)$ \\
Hands not washed & $2(6.7)$ & 0 & $5(16.7)$ \\
Adherence to aseptic technique & $28(93.3)$ & 0 & $1(3.3)$ \\
Work surface not cleaned & $16(53.3)$ & $9(30)$ & $21(70)$ \\
\hline
\end{tabular}

Table (4) indicates the paired t test for cultures, knowledge and practice through the pretest, posttests one and two of the study participants. The study findings revealed highly significant differences between pretest and posttest one of knowledge, pretest and posttest one of practice and posttests one and two of practice $\mathrm{P}<0.01$. Also, a significant difference was found between peritonitis episode of the pretest and posttest one $\mathrm{P}<0.05$ while there were no significant differences showed between peritonitis episode of the posttests one and two or between posttests one and two of knowledge $\mathrm{P}>0.05$.

Table 4. Paired t test for peritonitis episode, knowledge and practice at the pretest and posttests one and two of the study participants $(n=30)$.

\begin{tabular}{lc}
\hline Variable & t test (P value) \\
\hline Pretest and posttest one of peritonitis episode & 2.693 \\
Posttests one and two of peritonitis episode & $(0.012) \mathrm{S} * *$ \\
& $-.441-$ \\
Pretest and posttest one of knowledge & $(0.662) \mathrm{N} . \mathrm{S}^{* * *}$ \\
& $-27.892-$ \\
Posttests one and two of knowledge & $(0.000) \mathrm{H} . \mathrm{S}^{*}$ \\
& 1.459 \\
Pretest and posttest one of practice & $(0.155) \mathrm{N} . \mathrm{S}^{* * *}$ \\
& $-8.475-$ \\
Posttests one and two of practice & $(0.000) \mathrm{H} . \mathrm{S}^{*}$ \\
\end{tabular}

H.S $*=$ highly significant at the 0.01 level. $\mathrm{S} * *=$ Significant at the 0.05 level. N.S*** = no significant

\section{Discussion}

In viewing repetition of peritonitis episodes bring about unfavorable pathway for PD patient. More than one third of PD patients' were cared and managed by family caregivers in the present study. The mean age score was 26 years and, two third of them were males in consideration that they represent the vital age group in communities.

The nurse was the source for only $30 \%$ of the study participants and uninterestingly that $(6.7 \%)$ were receiving their educational needs from previous patient. In context of compliance and re-training needs of patients on PD through the assessment of patient knowledge and patient behavior [10] observed that the greater need for re-training was for younger patients with lower education degree. Meanwhile, a qualitative study done by [5] explored patients' experiences of peritoneal dialysis at home. The researchers mentioned that the nurses, due to their proximity with PD patients, they play a decisive role in the educational process, offer consistent and individualized assistance towards self-care.

Concerning, the peritonitis episode in the present research, it was declined from ( $30 \%$ to $10 \%)$ after three months from the posttest one, then increased to (13.3\%) after six months from the posttest one. These episodes of peritonitis were showed in significant difference with level of knowledge as well as the practice specifically. Some of the variables that showed level of noncompliance and associated with risk for peritonitis episode of the study participants' include; knowledge about infection control, hands not washed, adherence to aseptic technique and work area not cleaned. These finding was consistent with [11], who found that the technique skill was similar across all the steps of the procedure. The most common improperly performed steps were: not putting on a face mask, not flushing the tubing system, and not washing hands. In addition to peritonitis occurred in $60 \%$ of poor performers, whereas fully compliant patients had no peritonitis. Also, they concluded that adherence to recommended aseptic technique is the cornerstone of peritonitis prevention. In line with [12-13] who observed that the overall improvement of clinical outcome of PD patients lead to decreasing the peritonitis episode and the factors affecting peritonitis should be corrected. [14] Recommended that the PD patients and their caregivers should be educated about the importance of hygiene and exchanging methods to decrease the peritonitis episode. In addition, prolonging PD treatment, patients and caregivers alike are in need to receive intensive education in preventing and treating peritonitis.

Based on their study, [15] suggested that it should look to the units and countries with lower peritonitis episodes to see if it can adopt successful elements of their practice before resigning ongoing peritonitis burden. Also, [16] described the characteristics of the education programs used in Italian PD-centers, evaluating a possible relationship between programs and peritonitis rates. They found that training occurs in all the centers, while pre-dialysis education, home visits and re-training take place; a lower peritonitis rates proves to be correlated to these activities rather than to presence of specialized personnel, to ratio nurses-patients or training time. The present study findings revealed highly significant differences between pretest and posttest one of knowledge, pretest and posttest one of practice and posttests one and two of practice. Also, a significant difference was found between peritonitis episode of the pretest and posttest one while there were no significant differences showed between peritonitis episode of the posttests one and two or between posttests one and two of knowledge. Indeed [11] stressed on the importance of adequate training and retraining which is critical to the goal of decreasing the risk of peritonitis and maintaining the viability of the peritoneal membrane. As adherence of the 
procedure can be improved by retraining, compliance is a modifiable risk factor for peritonitis.

The main limitation of the present study was the small sample which limits generalization of the study findings.

\section{Conclusion and Recommendation}

A positive impact was showed on minimizing peritonitis episode in PD patients following home education in the present research but by time passed the patients' compliance declined, thus periodical refreshment home education provided by experienced nurses may be critically required to keep standardized PD practice. Also, performing of public health awareness by mass media, distribution of brochures and pamphlets may found beneficial for those targets. Further research is needed with larger sample to study peritonitis episodes and risk factors.

\section{References}

[1] Almutary H. H, Bonner A and Douglas C. Chronic Kidney Disease in Saudi Arabia: A Nursing Perspective. Volume 6 Issue 4 Middle East Journal of Nursing Volume 7 Issue 6. Education and Training. Dec 2013.

[2] Al-Sayyari, A. A., \& Shaheen, F. A. End stage chronic kidney disease in Saudi Arabia. A rapidly changing scene.Saudi medical Journal,32(4),339-346. 2011

[3] Saudi J Kidney Dis Transpl. Dialysis in the Kingdom of Saudi Arabia. Saudi J Kidney Dis Transpl;24:853-61 2013

[4] Kerschbaum J, König P , and Rudnicki M. Risk Factors Associated with Peritoneal-Dialysis-Related Peritonitis. International Journal of Nephrology. http://dx.doi.org/10. Volume 2012

[5] Sadala, M. L. A, Bruzos, G. A. de S, Pereira, E. R; Bucuvic, E. M. Patients' experiences of peritoneal dialysis at home: a phenomenological approach. Rev. Latino-Am. Enfermagem vol.20 no.1 Ribeirão Preto . 2012.http://dx.doi. Jan./Feb 2012.

[6] Ur-Rehman K.1, Housawi, A, Al-Jifri A, Kielar, M, Al-Ghamdi S. M. Peritoneal dialysis for chronic kidney disease patients: a single-center experience in Saudi Arabia Saudi J Kidney Dis Transpl. May;22(3):581-6. 2011
[7] Crabtree, J.H, Firanek, C.A, Piraino, B, Abu-Alfa, A.K, Guest, S. Access care \& complications management update 2012. Care of the Adult patient on peritoneal dialysis. Based in part on recommendations from the international society for peritoneal dialysis. Baxter Healthcare Corporation. (2012).

[8] Mahmud, K Techniques for peritoneal dialysis. Al-Mansoura University-Egypt. http://youtu.be/3UrrEIx0BSA. (2012).

[9] Bernardini J. Price V, Figueiredo A.ISPD Guidelines/Recommendations. Training guidelines. Peritoneal Dialysis Patient Training, Perit Dial Int:26(5); 625-632. www.ISPD.org, 2006

[10] Russo, R, Manili, L, Tiraboschi, G, Amar, K, De Luca, M, Alberghini, E, Ghiringhelli, P, De Vecchi, A, Porri, M.T, Marinangeli, G, Rocca, R, Paris, V, and Ballerini, L.Patient re-training in peritoneal dialysis: why and when it is needed. Kidney Int Suppl. Nov; (103):S127-32, 2006

[11] Mawar, S, Gupta, S, Mahajan, S.Non-compliance to the continuous ambulatory peritoneal dialysis procedure increases the risk of peritonitis. Int Urol Nephrol.;44(4):1243-9. Epub, Aug 2012

[12] Sharon J. N, Joanne M. B, Peter C. A, Rosane N, Sarbjit V. JPredictors of Peritonitis in Patients on Peritoneal Dialysis: Results of a Large, Prospective Canadian DatabaseClin J Am Soc Nephrol. ; 4(7): 1195-1200.doi: 10.2215/CJN.00910209..2009.

[13] Alwakeel J S , Alsuwaida A, Askar A, Memon N, Usama S , Alghonaim M , Feraz A N, Shah I Hamid, Wilson, H. Outcome and complications in peritoneal dialysis patients: A five-year single center experience.,vol: 22,Issue:2, Page:245-351. 2011.

[14] Liawnoraset, W. Prevalence and factors affecting peritonitis in CAPD patients in Maharat Nakhon Ratchasima Hospital under universal coverage scheme during 2008-2010: a three-year experience. J Med Assoc Thai.;94 Suppl 4:S19-24. Sep 2011

[15] Brown, M.C, Simpson, K, Kerssens, J.J, Mactier, R.A. Peritoneal dialysis-associated peritonitis episodes and outcomes in a national cohort are not improving in the post-millennium (2000-2007). Perit Dial Int. 2011 Nov-Dec;31(6):639-50. doi: 10.3747/pdi.2010.00185. Epub, 312011 .

[16] Bordin, G, Casati, M, Sicolo, N, Zuccherato, N, and Eduati, V. Patient education in peritoneal dialysis: an observational study in Italy. J Ren Care.;33(4):165-71. Oct-Dec 2007. 